\title{
Re-consideration of the Cultivation of Chinese College Students' Critical Thinking
}

\author{
Ge Qian ${ }^{1,2}$, Fu Hailun ${ }^{1}$, Hu Mingtao ${ }^{3}$ \\ ${ }^{1}$ School of Mathematics and Statistics, Shandong Normal University, Jinan, 250358, China \\ ${ }^{2}$ School of Science, Shandong Jianzhu University, Jinan, 250101, China \\ ${ }^{3}$ Shandong Education Press, Jinan, 250001, China
}

Keywords: Critical thinking, Cultivation, Higher education

\begin{abstract}
Critical thinking is the basic quality required by talented people and therefore the strategy of training college students' critical thinking has accordingly become an increasingly important research subject. In the process of speeding up the reform of higher education, it is necessary to fully recognize the importance of cultivating college students' critical thinking. There are three main ways to train students' critical thinking, but there may be many difficulties in integrating the training of critical thinking into the whole education system. It is necessary to carry out targeted reform strategies from such aspects as training objectives, training mode, educators and training targets.
\end{abstract}

\section{Introduction}

As a unique way of thinking, critical thinking is a basic ability of human beings. It is the precondition for the independence of human thought and the innovation of ideas. It is also a significant sign that human thinking is different from artificial intelligence. Critical thinking is a kind of rational thinking and scientific thinking, as one of the basic qualities of talented people. It has also aroused more and more attention in western education over the years. Many western countries have listed critical thinking as one of the goals of higher education. They take critical thinking as a comprehensive thinking to understand and to develop, and take it as a part of the learners' personality growth and self-improvement. China's research on critical thinking started later than western countries', but now critical thinking has been formally included in the composition of college student education and it has gradually become a part of quality and innovative education. Critical thinking has attracted more and more attention from Chinese educators.

\section{The necessity of cultivating the critical thinking of college students}

"Critical thinking is the purposeful, self-regulatory judgment." [1] It is of great significance in the ever-changing information society. But critical thinking does not exist in every individual, and each individual can only be said to be a critical thinker to some extent. Therefore, critical thinking needs to be taught and even cultivated for life. As one of the core skills of education in modern times, critical thinking has become an indispensable part of higher education. Educators and policy makers of education agree that enabling students to think critically is one of the major goals of education.

In the early 1990s, the United States government set the general goals for universities, in which especially emphasized the priority of developing the advanced thinking ability of college students. It proposed that the proportion of college students with critical thinking, effective communication and problem-solving ability should increase significantly by 2000. Former U.S. presidents Bill Clinton and George W. Bush both supported that higher education should prioritize the development of students' critical thinking. In 1993, Undergraduate Education Strategic Planning Committee of Princeton University proposed 12 measures for undergraduates, the second of which was "the ability to reason critically and systematically". With the development of the times, critical thinking 
education has been highly valued in recent years in the educational circles of western countries represented by the United States. They advocate that critical thinking and problem-solving should be listed as two basic skills of thinking. As a result, not only universities but also some primary and secondary schools have started to offer related courses to improve the quality of students' critical thinking. Many teachers in universities, secondary schools and primary schools have started to try to encourage students' critical thinking in their classes.

In today's society, more and more people have come to realize that critical thinking and innovative education are indispensable cornerstones and propellants for scientific progress and social development in this competitive era. But critical thinking is still a very scarce commodity in China, which is restricting China's independent development. In the 2012 China SAT annual report released by Duke International's education, a surprising result was that fewer than $7 \%$ of Chinese students who took the college entrance exam in the United States achieved a score above 1,800, and only $2 \%$ achieved more than 2,000 , which is commonly required by high-quality universities in the United States. According to the experts, this gap mainly comes from the reading and writing sections that examine students' critical thinking ability. This result shows that China's education system lacks the training of critical thinking, which is in contrast to the vigorous "education movement of critical thinking" in the international community. This disappointing situation has caught the attention of the relevant departments in China, the ministry of education of cultural quality education of institutions of higher learning committee and critical thinking and innovation education committee were set up in 2013. From then on, critical thinking has become part of the college students' cultural quality education. This will vigorously promote the work of critical thinking education.

Among all the stages, college stage is the most important stage for cultivating critical thinking. In 1954, Dressel et al. conducted a survey on critical thinking among more than 1,700 students in 11 universities, the results showed that the score of senior students was 19 percentage points higher than that of freshmen. In 1968, Lehman's survey also showed that college students got more than 34 percent of the critical thinking from entering school to graduating. Therefore, in the process of accelerating the reform of higher education, we should fully recognize the importance of cultivating students' critical thinking, apply it to teaching and learning, strengthen the research on critical thinking and relevant education practices, and take effective measures to promote the development of students' critical thinking.

\section{The way to cultivate the critical thinking of college students}

Over the years, many education researchers, philosophers and psychologists have conducted a lot of experiments and debated on the cultivation of critical thinking and put forward many valuable opinions. In general, there are three main methods to cultivate critical thinking of college students.

The first method is called the general method, that is, setting up courses separately to train critical thinking. This method doesn't involve much more specific subject content, but focuses on training critical thinking methods and principles applicable to different environments. Since logic is a discipline to study thinking, logic teaching is often used as an important means to cultivate students' critical thinking in western countries. The logic course includes formal logic and non-formal logic. The courses of critical thinking include argumentative logic, non-formal logic, logic and dialectics, critical reasoning, critical thinking and so on. In addition, cooperating with the course teaching, there are also some classic critical thinking textbooks in western countries, such as "Critical Thinking" written by Brooke Noel Moore and Richard Parker. This book is the best-selling college textbook in United States, it has been reprinted nine times. The two authors intuitively explained the basic problems, views, methods and techniques of critical thinking, correct reasoning and reasonable argument in simple and vivid language.

Some famous universities in China also offer courses related to critical thinking. For example, Peking University first offered the course of "Logic and Critical Thinking" in 2003. Since 2004, this course has been included in the summer school curriculum, with two rounds of teaching every year. The students of the "Yuanpei Program" are taught in the spring term, and the first-year students of 
other departments are taught in summer term. Since 2000, China Youth University of Political Studies began to reform the teaching of "General Logic" and gradually moved to the "Critical Thinking" course. In the autumn of 2003, this university started to offer the "Logic and Critical Thinking" course synchronously with Peking University. On the basis of summarizing the curriculum and teaching practice, Professor Gu Zhenxie wrote the book "Critical Thinking Tutorials" [2].

Through this method of cultivating college students' critical thinking, a complete curriculum system with clear purpose can be established, this is conducive to improving the system of critical thinking training. However, establishing separate courses requires specialized teachers to do the work in this field and needs to be supported by additional education resources. In addition, for students, the new courses will increase the burden on them.

The second method is to combine the teaching of critical thinking with subject teaching and train students' critical thinking in specific ways. Each course is a powerful vehicle for developing critical thinking, because the imparting of various kinds of knowledge cannot leave questions, denial or criticism. Conversely, critical thinking is also a necessity to complement to the professional knowledge of students. It not only helps students learn professional knowledge, but also helps them solve and think about problems encountered in daily life. Therefore, it is feasible and necessary to combine the cultivation of critical thinking with subject teaching. Specifically speaking, there are two combination methods, one of which is the immersion method. That is, teachers do not clearly teach the general principles of critical thinking, but subconsciously arouse and develop students' critical thinking through the teaching of subject knowledge. The other method is instillation, which means teaching the general principles of critical thinking clearly in the course teaching and encouraging students to think critically. Both of these methods call for an innovative classroom culture, which requires teachers to guide students to change from passive to active. Students should boldly challenge, explore its authenticity and pursue the concepts that they have never encountered before. Through continuous attempts and reflection, they will gain professional knowledge and enhance their critical thinking ability.

This training mode puts forward higher requirements for professional teachers. If they have in-depth studies and studies on the theory and practice of critical thinking, and can identify the organic link between critical thinking and subject teaching, then critical thinking training combined with subject teaching would be the ideal method. This method is conducive to the long-term development of critical thinking training and can effectively overcome the difficulties in setting up a separate critical thinking course.

The third method is to cultivate students' critical thinking by developing implicit courses, such as academic reports, symposiums, social practice and community activities. As a unique way of thinking, the formation of critical thinking is a long-term process, which requires constant development. Therefore, it is extremely important to create a school environment, social environment and family environment conducive to critical spiritual growth, so as to develop students' critical thinking.

Taking Harvard University as an example, its core courses are divided into seven categories: literature and art, historical research, foreign culture, moral reasoning, quantitative reasoning, social analysis, and science, each of which contains several courses of different levels and themes. Through different academic perspectives, academic cultures of different countries and regions, students are trained to think in different forms and themes. This university believes that the significance of teaching lies in teaching students diverse ways of thinking, so that students can truly master the methods of acquiring knowledge. These education methods and concepts coincide with the spirit of critical thinking, give us a lot of enlightenment and experience in the cultivation of critical thinking.

Overall, with the deep study of critical thinking and the influences of postmodern psychological tendencies, the researchers tend to prefer the training method that combines the cultivation of critical thinking with subject teaching. This method can integrate the cultivation of critical thinking into the training system of higher education, to improve students' critical thinking ability step by 
step.

\section{The difficulties and countermeasures of cultivating college students' critical thinking}

From the educational background in China, the logical concept is relatively weak and lacks the consciousness of critical thinking in the thinking patterns of traditional Chinese culture, so the cultivation of critical thinking is fundamental. In 1996, Professor Liu Rude pointed out the importance of critical thinking and discussed the significance and approaches of the cultivation of critical thinking [3]. Other scholars such as Zhong Qiquan, Luo Qingxu and Zhu Xincheng also conducted in-depth studies on the cultivation and development of critical thinking [4]-[7], and proposed some meaningful methods. However, there are still many difficulties in integrating the cultivation of critical thinking into the whole education system.

First, in the macro environment of the higher education in China, the emphasis on the cultivation of critical thinking is far from enough, and the instructional opinions and plans are scarce. There are only a few universities that offer critical thinking courses. The importance of critical thinking has not struck a chord with teachers, and has not been universally recognized by educators.

Secondly, in theoretical research, the understanding and research on critical thinking in China is more about exploring the importance of critical thinking conceptually. There are problems such as macroscopic, fuzzy and the neglect of cognitive training of thinking. At the same time, there is lack of objective empirical research in the study of critical thinking training. In fact, all kinds of thinking training courses in China are in the initial stage, the training of students' thinking is relatively backward.

Thirdly, in the practice of education teaching reform, Chinese educators fail to link critical thinking with curriculum reform. Although some universities have carried out some reforms and practices on the cultivation of critical thinking, they have not integrated the cultivation of critical thinking into the reform of the whole curriculum system. In class, the teaching of knowledge still emphasizes the imparting of knowledge, the positive interpretation and inheritance, so that the students are always in a state of passive acceptance , they have few opportunities for reflection and criticism. Even if some schools offer so-called "innovation ability" training courses, they are just "full of talk" and do not exercise and improve students' thinking ability from the perspective of thinking training.

Finally, the deficiency of teachers' ability also severely limits the development of critical thinking training. The cultivation of critical thinking poses a great challenge to teachers. It requires teachers to subvert the "full capacity" teaching mode, give the classroom stage to students. It also requires professional teachers to conduct in-depth research and learning on the theory and practice of critical thinking, and then find the organic connection between critical thinking and subject teaching. As far as the current situation in China is concerned, there is still a big gap in the training of teachers, and there is no training course for teachers on critical thinking. Due to the lack of research and training in this field, teachers are willing but unable. Even if they recognize the importance of critical thinking training, it is difficult for them to carry out targeted training for students in teaching.

Difficulty is not a reason to remain stagnant, there are many foreign success stories for Chinese educators to learn from. Due to the current national conditions in China, most universities do not have the amenities to set up a separate critical thinking course, but can combine critical thinking training with subject teaching and develop students' critical thinking through the daily classroom teaching. Therefore, the focus of critical thinking at the present stage should be how to strengthen the cultivation of students' critical thinking in teaching and courses. We should start from the four aspects of cultivating objectives, cultivating models, cultivating people and cultivating objects, attach importance to thinking training and integrate critical thinking training into subject teaching.

First, we should set goals for critical thinking. In the new era, the demand for skills is more diversified, and the training objectives of all kinds of skills emphasizes the cultivation of innovative and applied skills. However, it cannot be ignored that critical thinking is also an important component of the quality of skills in the new era, which is closely related to the development of 
innovation ability. Therefore, when setting the personal training objectives and specific course objectives, we should fully embrace the requirements of critical thinking, improve the infiltration mechanism of critical thinking training, and make the cultivation of critical thinking take root in the process of skill training.

Second, we need to establish a suitable teaching model for the cultivation of critical thinking. The traditional lecturing and infusing teaching model is the biggest stumbling block for the development of critical thinking ability. What is needed in the cultivation of critical thinking is a diversified and personalized teaching model, which needs to fully mobilize the initiative, participation and flexibility of students' thinking. Moreover, the teaching materials, teaching methods, teaching process, teaching evaluation and other links should be changed to be conducive to the development of students' critical thinking. Teaching materials should be prepared according to students' aptitude, open and practical topics should be added. In the process of teaching, more research teaching, case teaching and debate teaching should be adopted to promote students' independent learning and their participation. In teaching evaluation, we should pay attention to multi-dimensional segmentation and value judgment of thinking ability, and adopt multi-level and process evaluation methods. Only when the goal of improving students' critical thinking ability runs through the whole process of teaching can the two sides of teaching truly resonate and develop together.

Third, we should improve teachers' diversified abilities. Critical thinking training needs high quality trainers, therefore, the improvement of teachers' teaching ability is particularly important. The improvement of teaching ability includes two aspects, one of which is the promotion of professional literacy. Critical thinking teaching needs a lot of professional knowledge as the foundation, needs to integrate the relevant subject matter, so it is more difficult than the single subject teaching. The other aspect is the improvement of the teaching ability of critical thinking. Only when teachers have received special training of critical thinking and have systematically and comprehensively mastered the principles and methods of critical thinking, can they consciously transplant it into classroom teaching activities and keep producing results.

Finally, we need to build an educational atmosphere conducive to the cultivation of critical thinking. The subjective initiative of training directly determines the development of critical thinking training, and the relatively relaxed learning environment on the university campus is a breeding ground for critical thinking. While integrating critical thinking into professional teaching, we should make full use of the third method to cultivate critical thinking. We should create a critical academic atmosphere through hidden courses such as academic reports, seminars and social practice, and then form a "critical and intelligent" teaching culture, allow students take the initiative to criticize, explore and innovate in an excellent academic environment and enhance the interest and enthusiasm of developing the critical thinking ability actively.

\section{Acknowledgements}

Fund Project: Key topic of the Ministry of Education "Research on methodology of applying mathematics history to mathematics education” (DHA130273).

\section{References}

[1] Peter A. Facione. "Critical Thinking: A statement of expert consensus for purposes of educational assessment and instruction (executive summary)" in The Delphi Report, Millbrae,CA: California Academic Press,1990.

[2] Z. X. Gu and Z. H. Liu, Critical Thinking Tutorials [M], Beijing University Press,Beijing, 2006.

[3] R. D. Liu, Critical thinking and its teaching [J], Teacher Education Research, 1996(4): 62-67.

[4]Q. Q. Zhong, Critical thinking and its teaching [J], Global Education, 2002(1): 34-38.

[5] Q. X. Luo, On the cultivation of critical thinking in college students [J], Research on Education 
Tsinghua University, 2000(4): 81-85.

[6] X. C. Zhu, On the cultivation of critical thinking in college students [J], Higher Education Exploration, 2002(2): 62-64.

[7] X. C. Zhu, Importance and Strategies: On Cultivating College Students' Critical Thinking [J], Journal of South China Normal University (Social Science Edition), 2006(3): 123-126. 